\title{
A clinico-surgical outcome of vaginal hysterectomy with or without hydro dissection: a Quasi experimental study
}

\author{
Kirti M. Hurakadli*, L. L. Pujari, Prashant G.
}

Department of Obstetrics and Gynecology, S. N. Medical College, Bagalkot, Karnataka, India

Received: 25 June 2018

Accepted: 26 July 2018

\section{*Correspondence:}

Dr. Kirti M. Hurakadli,

E-mail: mh_kirti@yahoo.co.in

Copyright: (C) the author(s), publisher and licensee Medip Academy. This is an open-access article distributed under the terms of the Creative Commons Attribution Non-Commercial License, which permits unrestricted non-commercial use, distribution, and reproduction in any medium, provided the original work is properly cited.

\begin{abstract}
Background: Vaginal hysterectomy -the signature operation of gynecologic profession, is a hallmark of gynecological extirpative hysterectomy surgery and surgical excellance1. In the era of minimal invasive surgery, Nondescent vaginal hysterectomy has evolved over the years and is opted over abdominal route. It is because of lower morbidity, less postoperative pain, more rapid return to normal activities and lesser hospital stay associated with this route of surgery. Practice of hydrodissection with diluted adrenalin has been noticed by few surgeons.

Methods: We did a retrospective analysis of 267 cases of vaginal hysterectomies in our hospital over a period of three years, regarding the benefit of hydro dissection in reducing the blood loss and time of surgery, so as to incorporate this technique on routine basis.

Results: Of 267 cases, NDVH was done in 107 (40.1\%) cases, and 160 (59.9\%) patients underwent vaginal hysterectomy with PFR. Of 267 cases, 121 (45.3\%) cases had hydro dissection. In 146 (54.7\%) cases hydro dissection was not done. The mean blood loss was significantly reduced in cases with hydro dissection to a mean of 1.07 mops when compared to cases with no hydro dissection-mean of 1.71 mops. Duration of surgery was also significantly reduced to a mean of 39.9 minutes in cases with hydro dissection when compared to cases with no hydro dissection with a mean of 46.3 minutes. There was no significant change in duration of hospital stay.

Conclusions: Hydro dissection with diluted adrenaline should be routinely practice by all vaginal surgeons to reduce the duration of surgery and intraoperative blood loss.
\end{abstract}

Keywords: Hydrodissection, NDVH, Vaginal hysterectomy

\section{INTRODUCTION}

Vaginal hysterectomy -the signature operation of gynecologic profession, is a hallmark of gynecological extirpative hysterectomy surgery and surgical excellance. $^{1}$

In the era of minimal invasive surgery, Nondescent vaginal hysterectomy has evolved over the years and is opted over abdominal route. It is because of lower morbidity, less postoperative pain, more rapid return to normal activities and lesser hospital stay associated with this route of surgery.
Vaginal hysterectomy is indicated in women with uterovaginal prolapse. Non descent hysterectomy can been done in most of benign cases of AUB, Fibroids, Chronic PID, Chronic cervcitis, postmenopausal endometrial hyperplasia, etc. Successful outcome with /without Concurrent oophorectomy depends on size of uterus, mobility, descent, expertise, experience and skill of the gynecologists.

Julian reported on the benefit of infiltrating the vaginal wall with mixture of $1 ; 200,000$ adrenaline in normal saline to control small blood vessel bleeding from the vagina. It also makes easy dissection through the 
avascular plane anterior and posterior to cervix, hence reduces the time of surgery. This study intends to highlight the benefit of hydro dissection in reducing the blood loss and time of surgery, so as to incorporate this technique on routine basis. ${ }^{1}$ Laparoscopic surgeons routinely use vasopressin during myomectomy, to reduce intraoperative blood loss.

In present study authors used conventional Adrenaline which was easily available and was cost effective. Few of predictable intraoperative side effects of Adrenaline like transient tachycardia, hypertension, and paradoxical bradycardia were noted which could be prevented by aspirating for blood before injecting and confirming the correct plane for injection. Anesthetists were informed of use of adrenaline and their role was important in maintaining intraoperative vitals.

\section{METHODS}

In this record based, case series study, 267 women who underwent vaginal hysterectomy from June 2014 to May 2016 at our hospital were included. Of 267 cases, NDVH was done in 107 (40.1\%) cases, and 160 (59.9\%) patients underwent vaginal hysterectomy with PFR. Of 267 cases, 121 cases had hydrodissection.50-60 ml of normal saline with adrenaline diluted to 1:200000 was used foe vaginal wall infiltration anteriorly and posteriorly.

Effect of the technique was observed w.r.t blood loss, duration of surgery, and hospital stay. Blood loss was measured in terms of number of fully soaked mops of size $15^{*} 15 \mathrm{~cm}$. Duration of surgery was calculated in terms of minutes from the time after draping and catheterization until vault closure in cases of NDVH or until PFR in cases of prolapsed uterus. Size of uterus was graded as atrophic, normal size, enlarged (less than 8 wks size) and as Big ( $<12 \mathrm{wks})$, after clinical bimanual examination.

\section{Statistical analysis}

Data was entered in Microsoft excel sheet and later analyzed using SPSS software version 19. Percentages and proportions are used to represent qualitative data. Mean and standard deviation is done to represent quantitative data. Chi-square test for qualitative data and unpaired students ' $t$ 'test was applied to measure the difference between the groups.

\section{RESULTS}

Of 267 cases studied -30 (11.2\%) patients were <35 yrs, $178(66.7 \%)$ were between $36-50$ yrs, 55 (20.6\%) patients were between 51-65 yrs; 4 (1.5\%) cases were $>66$ yrs. All the 30 young patients were multiparous women who denied conservative surgeries inspite of counseling and opted for hysterectomy. In 12 cases, the indication was chronic cervicitis, 10 cases-uv prolapsed, 8 had DUB and 2 of them were operated for chronic pelvic pain (Table 1).
Table 1: Age distribution.

\begin{tabular}{|lll|}
\hline Age(yrs) & Frequency & Percent $(\%)$ \\
\hline$\leq 35$ & 30 & 11.2 \\
\hline $35-50$ & 178 & 66.7 \\
\hline $51-65$ & 55 & 20.6 \\
\hline$>66$ & 04 & 1.5 \\
\hline Total & 267 & 100.0 \\
\hline
\end{tabular}

Of 267 cases, 104 (39\%) had atrophic uterus, 79 (29.6\%) had normal sized uterus, $66(24.7 \%)$ had enlarged uterus, and $18(6.7 \%)$ patients had uterus size between 8-12 wks (Table 2).

Table 2: Age versus size of uterus.

\begin{tabular}{|c|c|c|c|c|}
\hline $\begin{array}{l}\text { Age } \\
\text { (yrs) }\end{array}$ & Atrophic & Normal & Enlarged & Big \\
\hline$<35$ & $\begin{array}{l}01 \\
(3.3 \%)\end{array}$ & $\begin{array}{l}08 \\
(26.7 \%)\end{array}$ & $\begin{array}{l}17 \\
(56.7 \%)\end{array}$ & $\begin{array}{l}04 \\
(13.3 \%)\end{array}$ \\
\hline $36-50$ & $\begin{array}{l}57 \\
(32.0 \%)\end{array}$ & $\begin{array}{l}67 \\
(37.6 \%)\end{array}$ & $\begin{array}{l}41 \\
(23.0 \%)\end{array}$ & $\begin{array}{l}13 \\
(7.3 \%)\end{array}$ \\
\hline $51-65$ & $\begin{array}{l}43 \\
(78.2 \%)\end{array}$ & $\begin{array}{l}03 \\
(5.5 \%)\end{array}$ & $\begin{array}{l}08 \\
(14.5 \%)\end{array}$ & $\begin{array}{l}01 \\
(1.8 \%)\end{array}$ \\
\hline$>66$ & $\begin{array}{l}03 \\
(75.0 \%)\end{array}$ & $\begin{array}{l}01 \\
(25.0 \%)\end{array}$ & 0 & 0 \\
\hline Total & $\begin{array}{l}104 \\
(39.0 \%)\end{array}$ & $\begin{array}{l}79 \\
(29.6 \%)\end{array}$ & $\begin{array}{l}66 \\
(24.7 \%)\end{array}$ & $\begin{array}{l}18 \\
(6.7 \%)\end{array}$ \\
\hline
\end{tabular}

Of 267 cases, NDVH was done in 107 (40.1\%) cases, and $160(59.9 \%)$ patients underwent vaginal hysterectomy with PFR. 12 pts aged less than 35 years had prolapsed/descent in young age-coz of multiparity and poor nutritional status. Majority of cases who underwent vaginal surgery were between 35-50 yrs (Table 3).

Table 3: Age versus descent.

\begin{tabular}{|llll|}
\hline $\begin{array}{l}\text { Age (yrs)/ } \\
\text { descent }\end{array}$ & $\begin{array}{l}\text { Non } \\
\text { descent }\end{array}$ & Prolapse & Total \\
\hline$<35$ & $18(60.00 \%)$ & $12(40.0 \%)$ & 30 \\
\hline $36-50$ & $80(44.9 \%)$ & $98(55.1 \%)$ & 178 \\
\hline $51-65$ & $09(16.4 \%)$ & $+46(83.6 \%)$ & 55 \\
\hline$>66$ & 0 & $04(100 \%)$ & 04 \\
\hline Total & $107(40.1 \%)$ & $160(59.9 \%)$ & $267(100 \%)$ \\
\hline
\end{tabular}

Four patients with postmenopausal bleeding underwent NDVH with BSO. Twelve patients with chronic PID underwent NDVH with B/L salpingectomy.

Table 4: Hydrodissection and blood loss (in terms of mops soaked).

\begin{tabular}{|lllll|}
\hline Size $/$ mops & 01 & 02 & 03 & Total \\
\hline Atrophic & $42(97.7 \%)$ & $01(2.3 \%)$ & 00 & 43 \\
\hline Normal & $34(97.1 \%)$ & $01(2.9 \%)$ & 00 & 35 \\
\hline Enlarged & $31(93.9 \%)$ & $02(6.1 \%)$ & 00 & 33 \\
\hline Big & $06(60 \%)$ & $04(40 \%)$ & 00 & 10 \\
\hline Total & $113(93.4 \%)$ & $08(6.6 \%)$ & 00 & 121 \\
\hline
\end{tabular}


Of 267 cases, $121(45.3 \%)$ cases had hydro dissection. In $146(54.7 \%)$ cases hydro dissection was not done. The mean blood loss was significantly reduced in cases with hydro dissection to a mean of 1.07 mops when compared to cases with no hydro dissection-mean of 1.71 mops (Table 4).

Table 5: Without hydrodissection and blood loss (mops soaked).

\begin{tabular}{|lllll|}
\hline $\begin{array}{l}\text { Size } \\
\text { /mops }\end{array}$ & 01 & 02 & 03 & Total \\
\hline Atrophic & $22(36.1 \%)$ & $38(62.3 \%)$ & $01(1.6 \%)$ & 61 \\
\hline Normal & $14(31.8 \%)$ & $27(61.4)$ & $03(6.8)$ & 44 \\
Enlarged & $11(33.3 \%)$ & $20(60.6 \%)$ & $02(6.1 \%)$ & 33 \\
\hline Big & $02(25.0 \%)$ & $05(62.5 \%)$ & $01(12.5 \%)$ & 08 \\
\hline Total & $49(33.6 \%)$ & $90(61.6 \%)$ & $07(4.8 \%)$ & 146 \\
\hline
\end{tabular}

Duration of surgery was also significantly reduced to a mean of 39.9 minutes in cases with hydro dissection when compared to cases with no hydro dissection with a mean of 46.3 minutes (Table 5).

Table 6: Hydrodissection and blood loss, time of surgery and hospital stay.

\begin{tabular}{|llllll|}
\hline \multicolumn{2}{l}{ Hydrodissection } & Number & Mean & $\begin{array}{l}\text { Std } \\
\text { deviation }\end{array}$ & $\begin{array}{l}\text { Std error } \\
\text { mean }\end{array}$ \\
\hline $\begin{array}{l}\text { Blood } \\
\text { Loss }\end{array}$ & No & 146 & 1.71 & 0.550 & 0.046 \\
\cline { 2 - 6 } Time & Nes & 121 & 1.07 & 0.250 & 0.023 \\
\cline { 2 - 6 } & Yes & 146 & 46.30 & 5.815 & 0.481 \\
\hline $\begin{array}{l}\text { Hospital } \\
\text { stay }\end{array}$ & No & 146 & 49.92 & 5.041 & 0.458 \\
\cline { 2 - 6 } & Yes & 121 & 4.63 & 0.531 & 0.044 \\
\hline
\end{tabular}

There was no significant change in duration of hospital stay (Table 6). The mean blood loss was $1.07 \pm 0.25$ mops with hydro dissection when compared to without hydro dissection $-1.71 \pm 0.55$ (p value-0.0001-statistically significant). Duration of surgery was reduced with hydro dissection with mean of $39.92 \pm 5.04$, which was statistically significant. There was no significant difference in the duration of hospital stay (Table 7).

Table 7: Hydrodissection and blood loss, mean duration of surgery and hospital time ( $T$ value and $P$ value)

\begin{tabular}{|lllll|}
\hline & Yes & No & T & P \\
\hline Blood loss (mps) & $1.07 \pm 0.25$ & $1.71 \pm 0.55$ & 11.9 & 0.0001 \\
\hline Duration & $39.92 \pm 5.04$ & $46.3 \pm 5.8$ & 9.48 & 0.0001 \\
Mean \pm SD & $4.63 \pm 0.56$ & $4.6 \pm 0.53$ & 0.43 & 0.66 \\
\hline Hospital stay & & & & \\
\hline
\end{tabular}

\section{DISCUSSION}

Various studies have been done evaluating the efficacy of the three routes of hysterectomy. A study in Assam concluded that patients requiring hysterectomy for benign non prolapsed cases may be offered the option of vaginal hysterectomy which has quicker recovery, shorter hospitalization; lesser operative and postoperative morbidity compared to abdominal route. ${ }^{2}$ Vaginal hysterectomy is the gold standard in the era of minimal access surgery. Some of the contraindications to $\mathrm{VH}$ can be overcome by assistance of laparoscope and a potential abdominal hysterectomy can be converted to a vaginal procedure. $^{3}$

Despite well-documented benefits of vaginal hysterectomy in terms of lower complication rates, shorter hospital stay and convalescence, and better quality of life, therefore, vaginal hysterectomy is preferred when either vaginal or abdominal route is clinically appropriate, the only formal guideline available is the uterine size guide line by ACOG which suggests that the vaginal route is the most appropriate in women with mobile uteri not larger than 12 weeks gestational age (approximately 280 grams). ${ }^{4,5}$ ACOG also acknowledges that the choice of approach should be based on anatomical condition, informed patient preference, and the surgeon's expertise and training. ${ }^{6}$

There are more studies on benefit of vasopressin in reducing blood loss when compared to conventional adrenaline. Vasopressin has longest clinical effect, but its systemic effects may be profound and pose significant challenges for the anesthesiologist and it can also sometimes cause lethal complications. The loss of peripheral pulse along with bradycardia, non-measurable arterial blood pressure, and cardiac complicationspulmonary edema, arrhythmia, and cardiac arrest has been reported after myometrial injection of vasopressin. ${ }^{7}$ Hence, we can expect the same vasoconstrictive side effects. Care should be taken to infiltrate a dilute solution with hemodynamic monitoring. To avoid unwanted surges in blood pressure, Nitroglycerine, which is a vasodilator, can be given in small aliquots. In rare instances, vasopressin-induced sympathetically mediated tachycardia predominates with hypertension. Here, a short acting beta blocker like esmolol may be useful in stabilizing the hemodynamics. The anti-diuretic activity of vasopressin can last for two to eight hours. This can be easily reversed with an intravenous diuretic like Frusemide. $^{8}$

Patients with a uterus $>14$ weeks, previous pelvic surgery, those requiring incontinence surgeries or pelvic floor surgery, were not included in the study which would have otherwise increased the blood loss and duration of surgery. Study on Hematocrit fall would have added value with respect to blood loss which was not done in this study.

\section{CONCLUSION}

In the era of minimal invasive surgery vaginal hysterectomy has evolved as a also a natural orifice surgery. With good resident training in vaginal hysterectomy, good pelvic anatomy orientation and skills, vaginal surgeons have introduced even radical surgeries 
in the past. Hydro dissection with diluted adrenaline should be practice by all vaginal surgeons to reduce the duration of surgery and intraoperative blood loss.

\section{ACKNOWLEDGMENTS}

Authors would like to thank postgraduate students, beloved House surgeons for retrieving and organizing the data and statistician for help in the analysis.

Funding: No funding sources

Conflict of interest: None declared

Ethical approval: Not required

\section{REFERENCES}

1. Rock JA, Jones HW. Te Linde's Opeartive Gynecology. 10 ${ }^{\text {th }}$ Editon. Chapter 32B. Lippincott Williams and Wilkins;2008:746.

2. Balakrishnan D, Dibyajyoti G. A comparison between non-descent vaginal hysterectomy and total abdominal hysterectomy. J Clin Diagn Res. 2016 Jan;10(1):QC11-4.

3. Panda S, Behera AK, Jayalakshmi M, Narasinga Rao T, Indira G. Choosing the route of hysterectomy. J Obstet Gynaecol India. 2015 Jul;65(4):251-4.
4. Kovac SR. Decision-directed hysterectomy: a possible approach to improve medical and economic outcomes. Int J Gynaecol Obstet. 2000;71:159-69.

5. Kovac SR, Barhan S, Lister M, et al. Guidelines for the selection of the route of hysterectomy: application in a resident clinic population. Am J Obstet Gynecol. 2002;187:1521-7.

6. ACOG Committee Opinion. Number 311, April 2005. Appropriate use of laparoscopically assisted vaginal hysterectomy. Obstet Gynecol. 2005;105:929-30.

7. Butala BP, Shah VR, Parikh BK, Jayaprakash J, Kalo J. Bradycardia and severe vasospasm caused by intramyometrial injection of vasopressin during myomectomy. Saudi J Anaesth. 2014 Jul;8(3):396-8.

8. Sinha M, Chiplonkar S. Anesthesia concerns in laparoscopic myomectomy. J Gynecol Endosc Surg. 2011 Jan;2(1):18-20.

Cite this article as: Hurakadli KM, Pujari LL, Prashant G. A clinico-surgical outcome of vaginal hysterectomy with or without hydro dissection: a Quasi experimental study. Int J Reprod Contracept Obstet Gynecol 2018;7:3668-71. 